CARDIOVASCULAR MEDICINE

\title{
Extracardiac vascular disease and effectiveness of sustained clopidogrel treatment
}

\author{
D Mukherjee, E J Topol, D J Moliterno, D M Brennan, K Ziada, L Cho, S R Steinhubl for \\ the CREDO Investigators
} See end of article for
authors' affiliations

\section{Correspondence to:} Dr Debabrata Mukheriee, Gill Heart Institute, Division of Cardiovascular Medicine, University of Kentucky, 900 S Limestone Street, 326 Wethington Building, Lexington, Kentucky 40536-0200, USA; Mukherjee@uky.edu

Accepted 20 April 2005 Published Online First 21 April 2005

Objective: To assess the effectiveness of long term treatment with clopidogrel of patients with extracardiac vascular disease (ECVD) (a history of either peripheral arterial disease or cerebrovascular disease). Design: Subgroup analysis of a prospective randomised clinical trial. Setting: The CREDO (clopidogrel for the reduction of events during observation) trial was a randomised, double blind, placebo controlled trial conducted at 99 centres in North America from June 1999 through April 2001.

Patients: 2116 patients who were to undergo elective coronary intervention or were deemed at high likelihood of undergoing percutaneous coronary intervention were enrolled in the CREDO trial. The current study sample consisted of 272 patients with ECVD.

Main outcome measure: One year incidence of the composite of death, myocardial infarction, or stroke in the intent to treat population.

Results: Patients with ECVD had a more than twofold greater relative risk reduction with clopidogrel for the primary end point compared with patients without ECVD $(47.9 \%$, $95 \%$ confidence interval $(\mathrm{Cl})-4.2 \%$ to $73.9 \%, v 18.2 \%, 95 \% \mathrm{Cl}-10.5 \%$ to $39.5 \%$, respectively).

Conclusions: Longer term clopidogrel treatment provides added protection against thrombotic events throughout the arterial vasculature, not limited to the coronary arteries, and may be especially effective for patients with more diffuse atherosclerosis such as ECVD.

E xtracardiac vascular disease (ECVD) is associated with an increased risk of in-hospital mortality and other complications after coronary interventions, independently of other co-morbidities and baseline characteristics. ${ }^{1-3}$ Treatments that may potentially improve clinical outcomes in this high risk cohort warrant further investigation. We analysed the effectiveness of long term treatment with clopidogrel of patients in the CREDO (clopidogrel for the reduction of events during observation) trial with ECVD (a history of either peripheral arterial disease or cerebrovascular disease). The study shows that patients with ECVD derive particular benefit from long term clopidogrel treatment.

\section{METHODS}

We hypothesised that patients with ECVD, being at high risk for cardiovascular events, would derive particular benefit from extended clopidogrel regimens. The design and methods of the CREDO trial have been previously described. ${ }^{4}$ Briefly, 2116 patients with symptomatic coronary artery disease and objective evidence of ischaemia who underwent elective percutaneous coronary intervention (PCI) or had a strong likelihood of undergoing PCI were enrolled from June 1999 to April 2001 from 99 centres in North America. Patients were randomly assigned to a loading dose of clopidogrel $(300 \mathrm{mg}$ ) or placebo 3-24 hours before PCI. All patients were given clopidogrel $75 \mathrm{mg} /$ day for 28 days after PCI. After this, the clopidogrel group (who were treated with the $300 \mathrm{mg}$ loading dose) continued receiving clopidogrel $75 \mathrm{mg} /$ day from day 29 through 12 months, whereas the control group (who received the placebo loading dose) received placebo for the same duration. All patients also were given aspirin daily. The primary end point of CREDO was a composite of one year death, myocardial infarction, and stroke. ${ }^{4}$ In this subgroup analysis, patients were categorised as having ECVD if they had a history of either peripheral arterial disease or cerebrovascular disease.

\section{Statistical analysis}

Baseline characteristics were compared by $\chi^{2}$ and Fisher's exact tests for discrete variables and Wilcoxon rank sum tests for continuous variables. Kaplan-Meier estimates and log rank tests were used to compare one year events between patients with ECVD treated with and those treated without long term clopidogrel. Hazard ratios and 95\% confidence intervals (CIs) were generated from Cox proportional hazards models. Relative risk reductions with corresponding 95\% CIs were calculated for patients with and without ECVD treated with long term clopidogrel. Lastly, risk adjusted hazard ratios were calculated for the composite events of death, myocardial infarction, stroke, and urgent revascularisation. A probability value of $\mathrm{p}<0.05$ was considered significant. Data were analysed with SAS 8.2 (SAS Institute, Cary, North Carolina, USA).

\section{RESULTS}

The study sample consisted of 272 patients with ECVD, 132 of whom received clopidogrel. Baseline demographic characteristics were similar in the patients with ECVD treated with and in those without clopidogrel (table 1), except that the clopidogrel group tended to be older.

The main CREDO trial observed an overall relative risk reduction of $26.9 \%$ ( $95 \%$ CI $3.9 \%$ to $44.4 \%$ ) in the one year primary composite end point (death, myocardial infarction, and stroke) with clopidogrel compared with placebo $(8.6 \% \mathrm{v}$ $11.8 \%, \mathrm{p}=0.02)$. Patients with ECVD had a more than

Abbreviations: $\mathrm{Cl}$, confidence interval; CREDO, clopidogrel for the reduction of events during observation; ECVD, extracardiac vascular disease; $\mathrm{PCl}$, percutaneous coronary intervention 
Table 1 Baseline characteristics of patients with a history of extracardiac vascular disease (ECVD) in the CREDO trial stratified by clopidogrel use

\begin{tabular}{|c|c|c|c|}
\hline & \multicolumn{2}{|l|}{ Clopidogrel } & \multirow[b]{2}{*}{ p Value } \\
\hline & $-(n=140)$ & $+(n=132)$ & \\
\hline Age (years) & $65.4(10.3)$ & $67.9(9.4)$ & 0.032 \\
\hline Women & $33.5 \%$ & $34.1 \%$ & 0.928 \\
\hline Weight $(\mathrm{kg})$ & $86.1(19.6)$ & $83.7(19.1)$ & 0.212 \\
\hline $\begin{array}{l}\text { Body mass index }>30 \\
\text { Risk factors }\end{array}$ & $41.7 \%$ & $37.2 \%$ & 0.438 \\
\hline Prior MI & $37.5 \%$ & $35.1 \%$ & 0.692 \\
\hline Diabetes & $32.3 \%$ & $32.5 \%$ & 0.972 \\
\hline Hypertension & $75.7 \%$ & $76.3 \%$ & 0.905 \\
\hline Smoking (within past year) & $32.8 \%$ & $27.3 \%$ & 0.330 \\
\hline Family history of heart disease & $47.1 \%$ & $48.6 \%$ & 0.804 \\
\hline Hyperlipidaemia & $71.8 \%$ & $76.5 \%$ & 0.383 \\
\hline \multicolumn{4}{|l|}{ Baseline medications } \\
\hline Aspirin & $28.6 \%$ & $34.1 \%$ & 0.326 \\
\hline$\beta$ Blocker & $65 \%$ & $63.6 \%$ & 0.814 \\
\hline Statin & $58.5 \%$ & $61.3 \%$ & 0.639 \\
\hline ACE inhibitor & $34.3 \%$ & $40.9 \%$ & 0.259 \\
\hline Calcium channel blocker & $46.4 \%$ & $37.1 \%$ & 0.120 \\
\hline \multicolumn{4}{|l|}{ Treatment after initial angiogram } \\
\hline $\mathrm{PCl}$ & $84.8 \%$ & 91.65 & 0.088 \\
\hline Medical treatment & $5 \%$ & $0 \%$ & 0.015 \\
\hline Bypass surgery & $3.57 \%$ & $3.79 \%$ & 1.000 \\
\hline \multicolumn{4}{|l|}{ Indications for $\mathrm{PCl}$} \\
\hline Recent MI & $5.1 \%$ & $8.5 \%$ & 0.124 \\
\hline Unstable angina & $62.7 \%$ & $50.8 \%$ & 0.124 \\
\hline Stable angina & 32.15 & $40.7 \%$ & 0.124 \\
\hline
\end{tabular}

Data are mean (SD) or percentages.

$\mathrm{ACE}$, angiotensin converting enzyme inhibitor; $\mathrm{MI}$, myocardial infarction; $\mathrm{PCl}$, percutaneous coronary intervention.

twofold greater relative risk reduction with clopidogrel for the primary end point compared with patients who did not have ECVD $(47.9 \%, 95 \%$ CI $-4.2 \%$ to $73.9 \%, v 18.2 \%, 95 \%$ CI $-10.5 \%$ to $39.5 \%$, respectively) as fig 1 shows. Overall event rates were significantly lower with long term clopidogrel treatment among patients with ECVD considering all possible composite ischaemic outcomes (table 2, fig 2).

A Cox proportional hazards analysis adjusted for age, diabetes, and history of prior myocardial infarction showed that clopidogrel treatment was associated with a substantially lower risk of death, myocardial infarction, stroke, and urgent target vessel revascularisation (odds ratio $0.49,95 \%$ CI 0.25 to $0.99, \mathrm{p}=0.04$ ) (table 3 ).

\section{DISCUSSION}

Clopidogrel pretreatment and long term treatment after PCI has been shown to reduce short term (30 day) and long term
Table 2 Clinical outcomes of patients with ECVD at one year assessed by the Kaplan-Meier method

\begin{tabular}{|c|c|c|c|}
\hline \multirow[b]{2}{*}{ One year outcome } & \multicolumn{2}{|l|}{ Clopidogrel } & \multirow[b]{2}{*}{ p Value } \\
\hline & $-(n=140)$ & $+(n=132)$ & \\
\hline Death & $2.96 \%$ & $1.57 \%$ & 0.454 \\
\hline $\mathrm{MI}$ & $14.57 \%$ & $8.42 \%$ & 0.133 \\
\hline TVR & $18.58 \%$ & $11.09 \%$ & 0.069 \\
\hline Stroke & $0.75 \%$ & $1.62 \%$ & 0.535 \\
\hline Death/MI & $16.71 \%$ & $9.22 \%$ & 0.080 \\
\hline Death/MI/TVR & $29.89 \%$ & $19.41 \%$ & 0.046 \\
\hline Death/MI/urgent TVR & $18.89 \%$ & $9.22 \%$ & 0.029 \\
\hline Death/MI/stroke & $17.45 \%$ & $9.22 \%$ & 0.058 \\
\hline Death/MI/stroke/urgent TVR & $19.63 \%$ & $9.22 \%$ & 0.020 \\
\hline
\end{tabular}

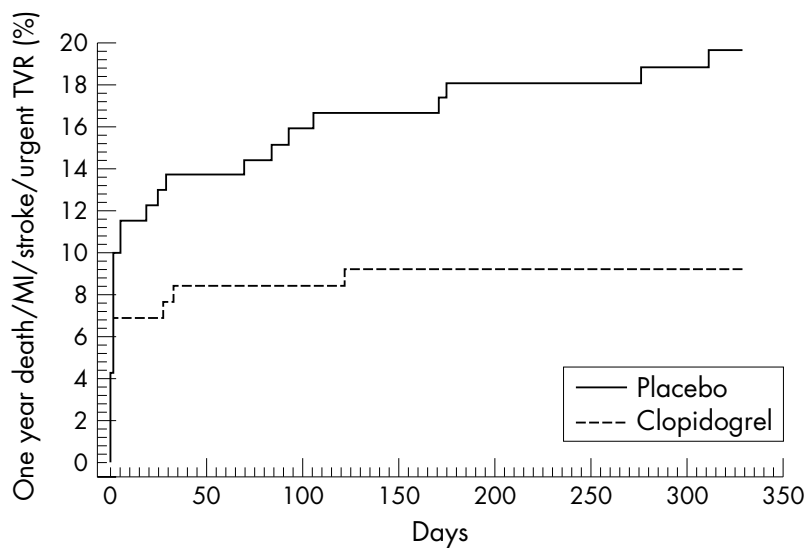

Figure 2 Kaplan-Meier curves showing significantly lower incidence of the composite of death, $\mathrm{MI}$, stroke, and urgent TVR in patients with ECVD treated with clopidogrel.

(eight months to one year) adverse cardiovascular outcomes. ${ }^{45}$ Clopidogrel treatment also improves clinical outcomes among patients undergoing peripheral vascular interventions. ${ }^{6}$ Our post hoc analysis of the CREDO trial suggests that long term clopidogrel treatment particularly benefits patients with ECVD. Peripheral arterial disease is a marker of systemic atherosclerosis and the presence of ECVD may conceivably be an indicator of more advanced, active, or aggressive vascular disease. ${ }^{67}$ Longer term treatment appears to provide added protection against thrombotic events throughout the arterial vasculature, not limited to the

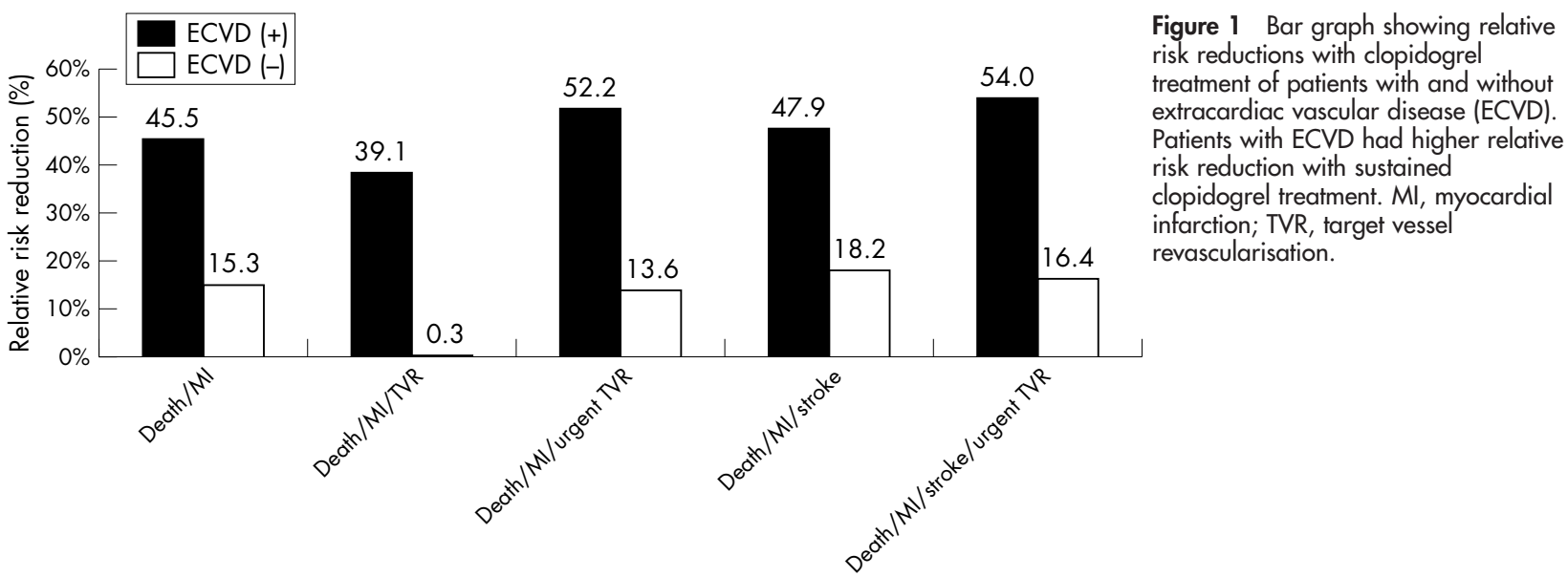


Table 3 Multivariate risk adjusted* hazard ratios (HR) of adverse clinical outcomes in patients with ECVD treated with clopidogrel

\begin{tabular}{lll}
\hline One year outcome & $\begin{array}{l}\text { Crude HR } \\
(95 \% \mathrm{Cl})\end{array}$ & $\begin{array}{l}\text { Adjusted HR } \\
(95 \% \mathrm{Cl})\end{array}$ \\
\hline Death/Ml/TVR & $0.61(0.37$ to 1.01$)$ & $0.61(0.36$ to 1.02$)$ \\
Death/MI/urgent TVR & $0.48(0.24$ to 0.95$)$ & $0.51(0.26$ to 1.04$)$ \\
Death/MI/stroke/urgent TVR & $0.46(0.23$ to 0.91$)$ & $0.49(0.25$ to 0.99$)$ \\
\hline *Adjusted for age, prior Ml, and diabetes. & \\
Cl, confidence interval. & & \\
\hline
\end{tabular}

coronary arteries, and may be especially effective for patients with ECVD.

Our study has inherent limitations given the post hoc analyses, thus precluding definitive conclusions. Because the ECVD group was not selected randomly, potential selection bias may exist. However, clopidogrel treatment was randomly assigned and blinded, so any bias should be balanced between the clopidogrel and control groups. Moreover, we used a risk adjusted Cox proportional hazards model to account for differences in baseline demographic co-morbidities, and long term treatment with clopidogrel remained a significant independent predictor of lower one year death, myocardial infarction, stroke, and urgent target vessel revascularisation.

\section{Authors' affiliations}

D Mukheriee, D J Moliterno, K Ziada, S R Steinhubl, Division of

Cardiovascular Medicine and the Gill Heart Institute, Lexington, Kentucky, USA

E J Topol, D M Brennan, Department of Cardiovascular Medicine, Cleveland Clinic Foundation, Cleveland, Ohio, USA

L Cho, Division of Cardiology, Loyola University Medical Center, Chicago, Illinois, USA

\section{REFERENCES}

1 Mukheriee D, Eagle KA, Smith DE, et al. Impact of extracardiac vascular disease on acute prognosis in patients who undergo percutaneous coronary interventions (data from the Blue Cross \& Blue Shield of Michigan Cardiovascular Consortium (BMC2)). Am J Cardiol 2003;92:972-4.

2 Rihal CS, Sutton-Tyrrell K, Guo P, et al. Increased incidence of periprocedural complications among patients with peripheral vascular disease undergoing myocardial revascularization in the bypass angioplasty revascularization investigation. Circulation 1999;100:171-7.

3 Sutton-Tyrrell K, Rihal C, Sellers MA, et al. Long-term prognostic value of clinically evident noncoronary vascular disease in patients undergoing coronary revascularization in the bypass angioplasty revascularization investigation (BARI). Am J Cardiol 1998;81:375-81.

4 Steinhubl SR, Berger PB, Mann JT 3rd, et al. arly and sustained dual oral antiplatelet therapy following percutaneous coronary intervention: a randomized controlled trial. JAMA 2002;288:2411-20.

5 Mehta SR, Yusuf S, Peters RJ, et al. Effects of pretreatment with clopidogrel and aspirin followed by long-term therapy in patients undergoing percutaneous coronary intervention: the PCI-CURE study. Lancet 2001;358:527-33.

6 Dey S, Mukherjee D. Clinical perspectives on the role of anti-platelet and statin therapy in patients with vascular diseases. Curr Vasc Pharmacol 2003; 1:329-33.

7 Hirsch AT, Criqui MH, Treat-Jacobson D, et al. Peripheral arterial disease detection, awareness, and treatment in primary care. JAMA $2001 ; 286: 1317-24$.

\section{IMAGES IN CARDIOLOGY}

\section{A contraindication for internal mammary to coronary bypass}

A 56 year old man suffered a Q wave myocardial infarction complicating a massive lower gastrointestinal haemorrhage, with postinfarction dyspnoea. He had bilateral lower extremity intermittent claudication despite femoropopliteal artery bypass grafting several years previously. Cardiac catheterisation was performed via the left brachial artery because of absent femoral pulses. There was severe global left ventricular systolic dysfunction, ostial left main coronary artery stenosis, right coronary artery occlusion, and there were suitable targets for coronary artery bypass grafting. The aorta was completely occluded below the renal arteries (Leriche phenomenon, panel A). Weak abdominal (ureteral) collateral arteries reconstituted the femoral arteries (arrowhead). A selective angiogram of the left internal mammary artery (LIMA, panel B) showed significantly more collateral supply from the left subclavian artery to the left femoral artery via the inferior epigastric artery.

Internal mammary collaterals to the femoral arteries are well described but little remembered. Surgical harvest of the LIMA for coronary artery bypass interrupts these collaterals and would likely precipitate limb threatening ischaemia.
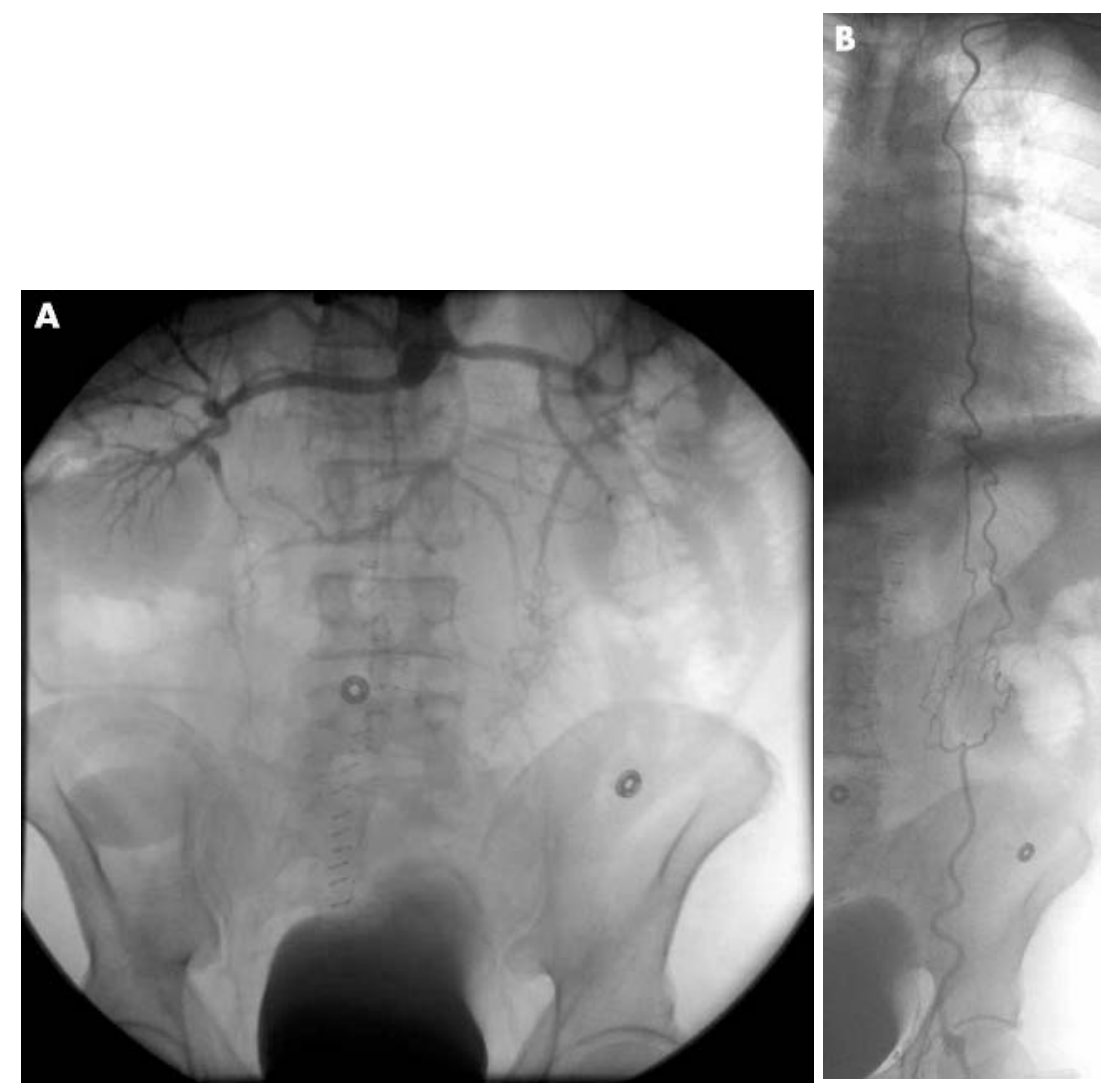

\section{R J Lederman} lederman@nih.gov 